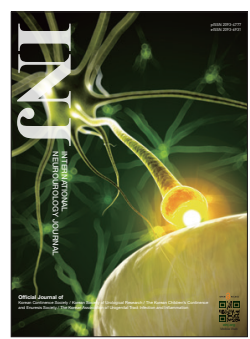

\title{
Comprehensive Review of Effective Application of Questionnaires for Clinical Research on Lower Urinary Tract Symptoms With Translation and Cultural Adaptation to the Korean Language
}

\author{
Jungyo Suh, Seung-June Oh, Sung Yong Cho \\ Department of Urology, Seoul National University Hospital, Seoul, Korea
}

\begin{abstract}
Lower urinary tract symptoms are highly prevalent and closely related to patients' quality of life. Clinical research on urologic disease is essential for accumulating evidence on patient management; however, the major obstacle is converting patients' subjective symptoms to objective parameters. The optimal application of well-developed and validated questionnaires is vital in achieving objectivity and minimizing bias in clinical research. Numerous questionnaires for measuring symptoms and quality of life in urologic diseases have been developed worldwide; however, they cannot be directly used in clinical studies without validation processes. This review aimed to explain the common procedures for translation, linguistic, and psychometric validation of developed questionnaires from other languages. Furthermore, we comprehensively reviewed currently available questionnaires for evaluating lower urinary tract symptoms in the Korean population.
\end{abstract}

Keywords: Surveys and questionnaires; Urinary bladder; Overactive; Lower urinary tract symptoms

- Conflict of Interest: No potential conflict of interest relevant to this article was reported.

\section{INTRODUCTION}

Lower urinary tract symptoms (LUTS) are a complex group of symptoms that result from diseases and medical conditions affecting the bladder and urethra. The International Continence Society (ICS) classifies LUTS into 3 categories - storage, voiding, and postmicturition symptoms [1]. LUTS are highly prevalent in the general population, with a prevalence of $64.3 \%$ $76.3 \%$ reported in previous studies [2,3]. Severe LUTS are negatively associated with quality of life (QoL) [4]; thus, proper management of LUTS is important for a patient's welfare.

LUTS are associated with urologic diseases, such as benign prostatic hyperplasia $(\mathrm{BPH})$ and overactive bladder $(\mathrm{OAB})$ [5].
$\mathrm{BPH}$ is predominantly characterized by the proliferation of smooth muscle and epithelial cells of the prostate transition zone [6], which is one of the most common urologic problems that cause LUTS in the elderly population [5,7]. OAB is clinically defined by the presence of urinary urgency, mostly cooccurring with urinary frequency and nocturia with or without urge urinary incontinence (UUI) $[8,9]$. Approximately $10 \%$ of worldwide general population have $\mathrm{OAB}$ symptoms, and it increased to $20 \%$ in 2018 [10].

To evaluate and diagnose LUTS, patients' medical history, laboratory tests, questionnaires, and function assessment tools, including uroflowmetry, frequency-volume chart, and urodynamic study, were analyzed [11-13]. Owing to the subjective na-

Corresponding author: Sung Yong Cho (D) https://orcid.org/0000-0001-9271-6951 Department of Urology, Seoul National University Hospital, 101 Daehak-ro, Jongno-gu, Seoul 03080, Korea

E-mail: moretry@yahoo.com

Submitted: March 2, 2020 / Accepted after revision: May 11, 2020 
ture of LUTS, the objective measurement of subjective symptoms by patient-reported outcome measurement tools (PROMs) is essential in the management of urologic disease and clinical studies [14]. Therefore, choosing appropriate questionnaires in a clinical trial is extremely important to determine the success or failure of clinical studies [15].

Numerous PROMs have been developed worldwide; however, none of the guidelines showed how to apply optimal PROMs for specific symptoms or diseases. In this review, we have explained previously established procedures for translation and linguistic validation of developed PROMs for other languages and suggested validated PROMs for common urologic diseases.

\section{TRANSLATION AND VALIDATION OF THE QUESTIONNAIRE IN FOREIGN LANGUAGE PIPELINES}

In most cases, using a formerly translated and validated questionnaire is a practical method to perform clinical studies and measure patient-reported outcomes (PROs). If there are no optimal questionnaires available in the Korean language, we can develop an in-house questionnaire or translate questionnaires to the Korean language. The development of the novel in-house questionnaire has many obstacles, owing to the difficulty in obtaining the validity, reliability, responsiveness, and interpretability of each statement [16]. Each process requires multiple efforts and time for in-house development using preexisting and already validated questionnaires might be a reasonable alternative. Moreover, using a multiculture, validated questionnaire is beneficial for a multinational, multicenter clinical trial design [15]. Numerous questionnaires have been developed and validated worldwide; thus, translating questionnaires in Korean is more effective than developing in-house questionnaires.

The translated version of the questionnaire does not guarantee equivalent accuracy in collecting patients' responses to the original version. A well-translated questionnaire provides the same meaning and uses appropriate idioms for each language [17] however, it is not easy. To develop a cross-cultural equivalent of the translated and original version of the questionnaire, linguistic and psychometric validation of the translated questionnaire is essential.

The first process, linguistic validation, has to follow the principles of good practice for translation and cultural adaptation (TCA) process for PROMs, which was announced by the International Society for Pharmacoeconomics and Outcomes Re- search task force [18]. The TCA framework for PROMs consists of 8 core steps: preparation, forward translation, reconciliation, back translation, harmonization, cognitive debriefing, proofreading, and final reporting. In the preparation phase of the TCA, the project manager should contact the copyright holder for approval of the use and translation of the questionnaire.

Forward translation and back translation must be performed by at least 2 independent translators: a professional translator and a native speaker of the target language and source language (Fig. 1). The reconciliation phase resolves the discrepancy between the forward translators by an independent bilingual, who was not exposed to the forward translation process. The most important part of this process is the reconciliation decision reviewed by the project manager. Back translation is a quality control step performed by at least one backward translator. Harmonization is essential in the TCA process, intensively reviewing and obtaining the equivalent of the source and translated versions of questionnaires by harmonization meetings with the project manager, in-country consultant, and translators.

Cognitive debriefing is the pilot testing of the translated questionnaire to at least 5-8 responders. The project manager assesses face validity, convergent validity, discriminant validity, responsiveness, test-retest, and internal consistency of each respondent. In this step, the project manager assesses that patients exactly understand the meaning of the contexts using responder's opinion and decide whether to revise the translated questionnaire. After reviewing and proofreading each step, the final version of the translated questionnaire is verified for use in the target country with the same quality of that of the source country questionnaire.

In the second phase of validation, psychometric validation is a more complex process for obtaining validity and reliability of the questionnaire (Fig. 2) [19]. The validity and reliability of the questionnaire need to be verified before application in clinical research. Validity refers to the accuracy, and reliability refers to the consistency of the instrument for evaluating symptom scores. The establishment of validity should be conducted in several ways, including assessing (1) construct, (2) content, (3) criterion, and (4) face validity.

Construct validity represents the relationship between the questionnaire score and the underlying hypothesis [20-22]. Content validity, also known as logical validity, indicates that the items of the questionnaire measure all components that are supposed to be measured [20]. Criterion validity measures the 

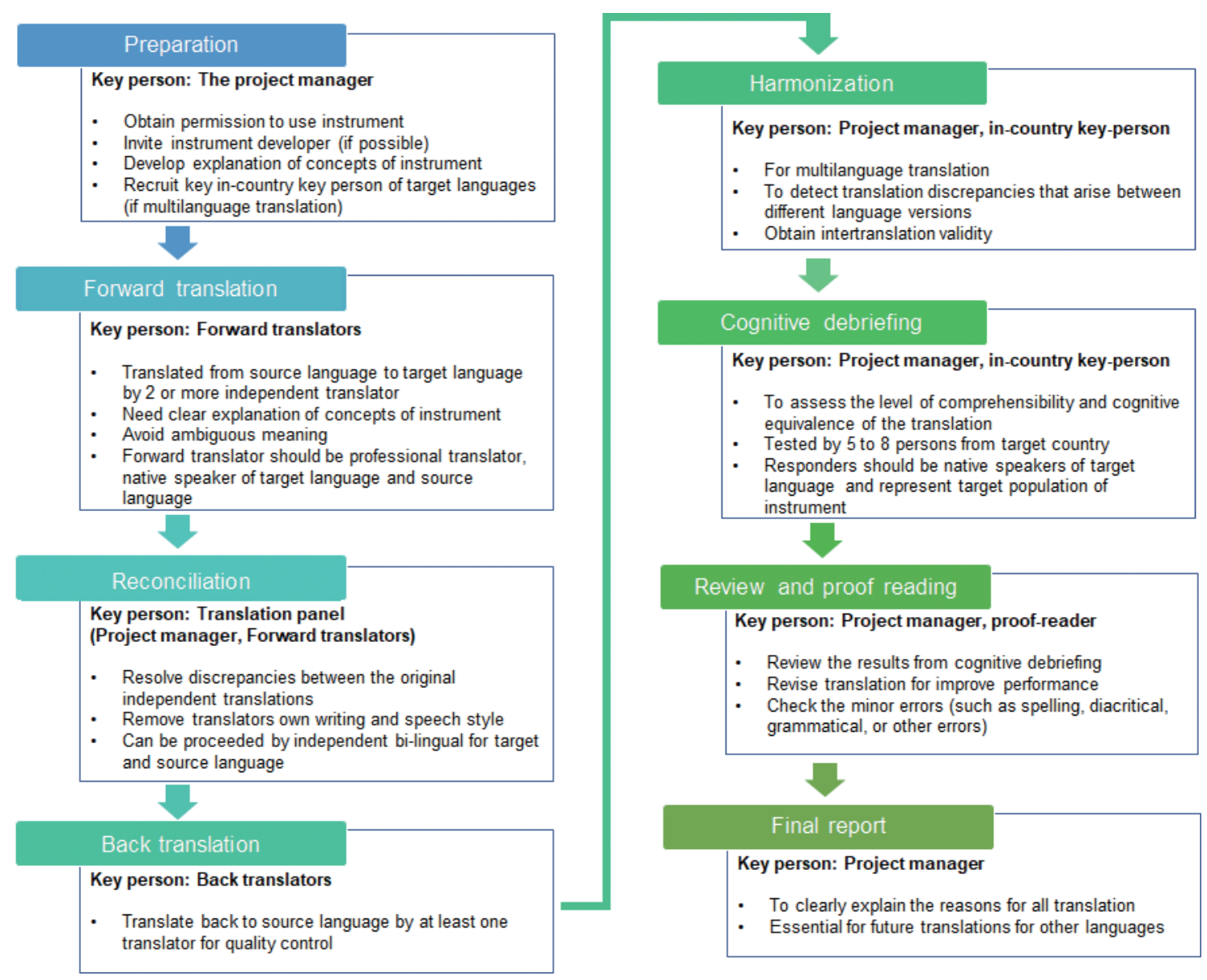

Fig. 1. Standard translation and linguistic validation process.

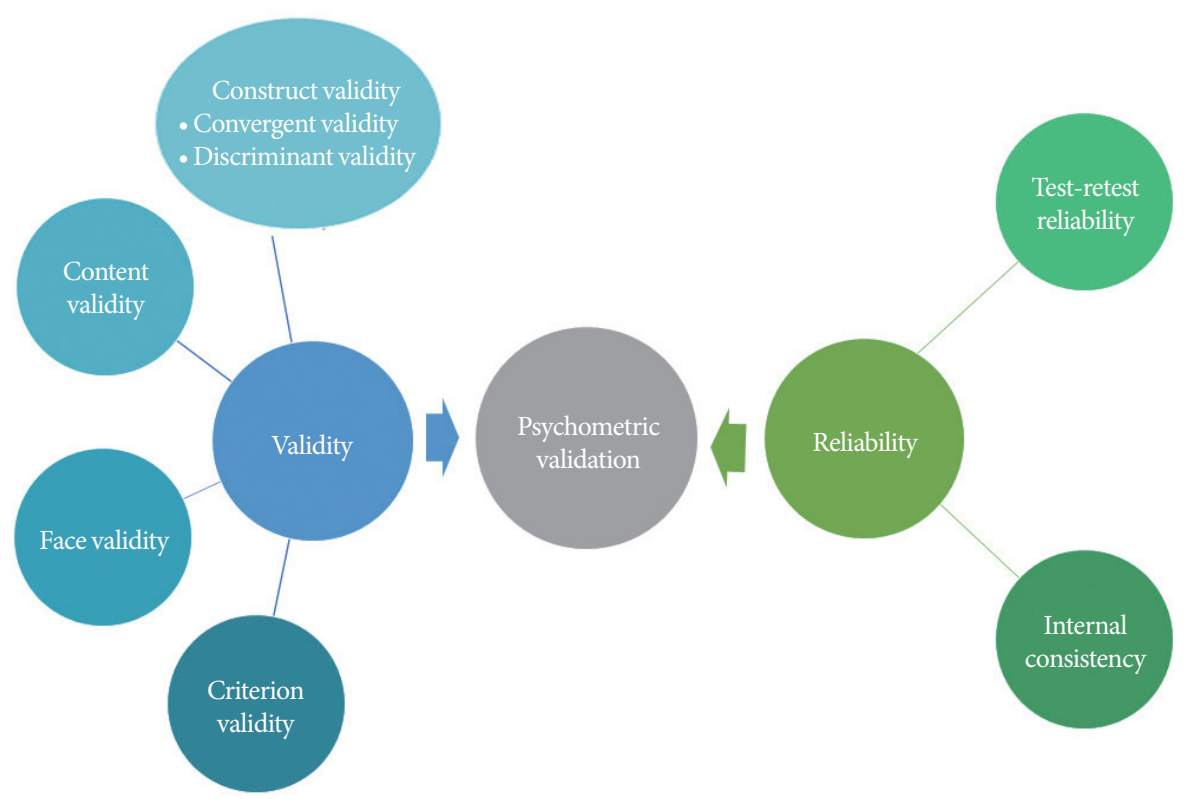

Fig. 2. Key features of psychometric assessment. 
relationship between the novel assessment tool and the current gold standard or another validated tool [22]. Face validity is the subjective view of responders' symptoms or patients' QoL, which is also supposed to be measured.

Reliability is another component of the psychometric performance measure of the developed questionnaire. Internal reliability refers to the consistency within the tests, which can be measured using statistical methods of Cronbach's alpha [20]. External reliability refers to the consistency between the tests, which can be assessed by test-retest reliability and interrater reliability $[19,20]$. After confirming linguistic validity and psychometric validity, the foreign language questionnaire is fully validated.

\section{OVERVIEW OF THE AVAILABLE QUESTIONNAIRE FOR KOREAN PATIENTS WITH LUTS}

From the late 1990s to early 2000, several novel anticholinergic drugs were introduced in the market and multinational, multicenter clinical trials were actively performed. The desire of the Korean Continence Society to participate in clinical trials on patients with $\mathrm{OAB}$ has increased. To quantify patients' subjective LUTS and their QoL for multinational clinical trials, validated Korean versions of international LUTS questionnaires were a prerequisite. However, no questionnaires had been validated by the society, and there was no experience of conducting validation of the questionnaires. In the early 2000s, Dr. SeungJune Oh was interested in validating the Incontinence Quality of Life (I-QOL) questionnaire on a personal level and directly contacted Health Research Associates Inc., Mountlake Terrace, WA, USA to conduct the full linguistic validation process to complete the Korean version of the I-QOL [23]. I-QOL was the first fully validated Korean version of the urinary incontinence questionnaire that was validated using a formal professional validation process. Based on his experience with the full linguistic validation process, Dr. Oh suggested to the Korean Continence Society (KCS) that he would organize taskforce teams to validate the Bristol Female Lower Urinary Tract Symptom (BFLUTS) [24] and King's Health Questionnaire (KHQ) [25] in Korean. The Korean versions of the KHQ and BFLUTS questionnaires are the first questionnaires that were linguistic and psychological validated by a multicenter study with the involvement of the KCS. Since then, validation studies of many other questionnaires initiated by Dr. Oh have also been conducted at the society or personal level. Consecutively, until the late 2000s, many international questionnaires required for clinical research have been validated in Korean, such as $\mathrm{OAB}$ questionnaire (OAB-q) [26], International Consultation on Incontinence Questionnaire (ICIQ), ICIQ-OAB, ICIQ for nocturia (ICIQ-N), ICIQ for male LUTS (ICIQ-MULUTS), Interstitial Cystitis Symptom Index (ICSI), and Interstitial Cystitis Problem Index (ICPI) [27], Urgency Perception Score (UPS) [28], Patient Perception of Bladder Condition (PPBC), Indevus Urgency Severity Scale (IUSS) [28], and OAB symptom score (OABSS) [29]. Since 2010, Korean versions of Patient Perception of Intensity of Urgency Scale (PPIUS), Pelvic Pain and Urinary/Frequency (PUF) [30], Urinary Tract Infection Symptoms Assessment (UTISA), Benefit, Satisfaction, and Willingness to Continue (BSW) [31], Overactive Bladder Satisfaction with Treatment Questionnaire (OAB-SAT-q) [32], and Expanded Prostate Cancer Index Composite for Clinical Practice (EPIC-CP) have been validated. The validated questionnaires obtained through this process played a decisive role in upgrading the level of clinical research on lower urinary tract dysfunction in Korean academic society.

Currently, there are approximately 30 available questionnaires for Korean patients with LUTS and neurogenic bladder (Table 1). The questionnaires focus on (1) objectifying the subjective symptoms, (2) scoring the degree of discomfort, and (3) assessing QoL and satisfaction. Most translated questionnaires are linguistically but not psychometrically validated. All questionnaires were freely accessible on the "Korean Continence Society (KCS)" official website (http://www.kcsoffice.org).

\section{Benign Prostatic Hyperplasia}

$\mathrm{BPH}$ is one of the most common urologic diseases in elderly men. To analyze symptoms of BPH, the International Prostate Symptom Score (IPSS), American Urological Association Symptom Score, Danish Prostate Symptom Score (DAN-PSS), BPH impact index, and ICS male [20] questionnaires are being used worldwide. There were no questionnaires that completed the validation process for translation. DAN-PSS is the only validated questionnaire but does not cover LUTS, only the sexual function component [33]. Among the BPH symptom questionnaires, only the IPSS has a Korean version. Although the translated version of the IPSS has not yet been confirmed by the linguistic validation process, it is widely used and accepted by Korean urologists. The IPSS has 5 statements for symptoms and one statement for QoL. The symptom statements score the severity from 0 to 5 , and the QoL statement scores the severity from 0 to 6 . 


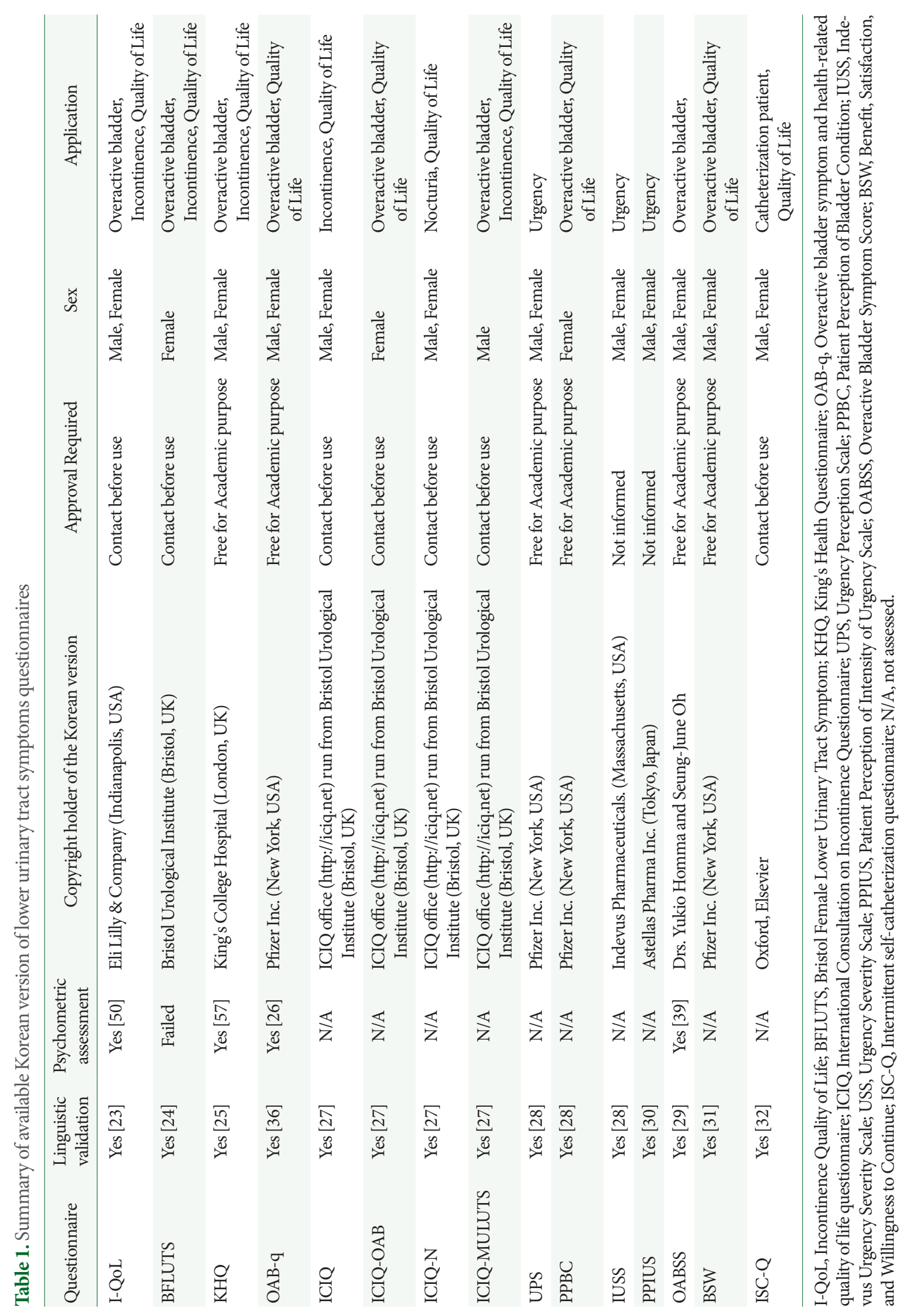


The sum of the total values of IPSS classified symptom severity was mild (0-7), moderate (8-19), and severe (20-35).

\section{Overactive Bladder}

$\mathrm{OAB}$ is common in both sexes, and the diagnosis of $\mathrm{OAB}$ is primarily based on patients' storage symptoms. Severe OAB causes UUI, which is related to aa reduction in QoL. Several questionnaires have been developed for measuring storage symptoms, incontinence, and QoL, which are important in the diagnosis, treatment, and surveillance of $\mathrm{OAB}$.

The OAB-q was developed to cover all OAB symptoms and QoL problems for both sexes [34]. This questionnaire has 33 statements; thus, obtaining a questionnaire in every clinical practice is extremely time-consuming. To resolve this problem, the OAB-q short form was developed to capture the full statements of OAB-q in a shorter time and with good reliability, validity, and responsiveness [35]. OAB-q is a self-filling type of questionnaire that consists of 2 major domains for measuring the modified $\mathrm{OAB}$ - a validated 8-question screen (OAB-V8) and health-related QoL (HRQoL). Each OAB-V8 statement was scored from 0 to 6 , and 2 points were added to the male responders. Clinicians diagnose $\mathrm{OAB}$ when the sum of the 8 statement scores is $>8$. The HRQoL domain has 4 subdomains: coping, concern, sleep, and social interaction. The OAB-q questionnaire translated and linguistic validated in over 14 languages [36]. Psychometric property of the Korean version of OAB-q was validated in 2012 [26].

The OABSS is a simplified version of the questionnaire that was developed in 2006. Homma et al. [37] developed this patient-scoring system, which is easy to use. The main concept of OABSS is based on core symptoms of OAB based on the ICS definition [9] - urinary urgency, usually with urinary frequency and nocturia, with or without UUI. Because OABSS has only 4 items, it is extremely easy to apply in a daily clinical practice with acceptable reliability. The severity of OAB symptoms is commonly classified according to the OABSS score - mild $(\leq 5)$, moderate (6-11), and severe $(\geq 12)$ [38]. The Korean version of the OABSS was validated both linguistically in 2008 [29] and psychometrically in 2014 [39].

\section{General Symptom Assessment}

The BFLUTS [21] questionnaire, which was developed to assess symptom severity, QoL, and treatment outcome, focuses on female LUTS and urinary incontinence. The BFLUTS questionnaire is self-administered by patients. The items of the BFLUTS questionnaire are based on the ICS male questionnaire [20] which was developed to measure the QoL and discomfort in male patients with LUTS. The BFLUTS questionnaire consisted of 4 domains (LUTS severity, sexual function, discomfort, and QoL) and 34 statements. The Korean version of the BFLUTS questionnaire was translated and validated in 2004 [24]. The BFLUTS results show good correlation with the pad test and frequency-volume chart; however, it takes a long time, because of the number of questions. A shorter version of the BFLUTS questionnaire is available: incontinence (BFLUTS-IS), voiding (BFLUTS-VS), filling (BFLUTS-FS), sexual function (BFLUTSsex), and QoL (BFLUTS-QoL) [40]. There was no information on the reliability of the BFLUTS questionnaire in male patients with $\mathrm{OAB}$.

The KHQ was developed by King's College Hospital to measure the QoL of female patients with incontinence. KHQ is a self-filling type of questionnaire that covers a broad range of QoL, impact on life, and general patients' perception of OAB [41]. The full version of the KHQ consisted of 9 domains (general health perception, impact on life, role limitation, physical limitation, social limitation, personal relationship, emotion, sleep/energy, incontinence severity) and 21 items. The KHQ is one of the most widely used questionnaires translated in various languages. The linguistic validation of the Korean version of the KHQ was performed in 2005 [25] and the reliability of KHQ for OAB symptoms was validated for both sexes [42].

\section{Urgency}

Urgency is the core symptom of $\mathrm{OAB}$, and the severity of urgency is directly associated with QoL [43]. Several questionnaires have been translated and linguistically validated in Korean.

The IUSS questionnaire focuses on urgency [44]. To reduce recall bias, IUSS measures patient-reported subjective symptoms by 4 degrees of severity: (1) no sensation of urgency, (2) awareness of urgency but easily tolerated, (3) urgency that is somewhat uncomfortable, and (4) extreme urgency with discomfort. The IUSS questionnaire shows reliable results when applied in randomized clinical trials to measure improvement in urgency severity in Korean patients [45].

The PPIUS is a single-item questionnaire focused on urgency symptoms and well-demonstrated symptom severity covering urgency and UUI [46]. The linguistic and psychometric validation of the Korean version was conducted.

The UPS is another single-item questionnaire to determine patients' perception of urgency and desire to urinate, which was 
developed in 2005 [47]. It was translated by the KCS and Pfizer Inc., and both Korean versions of the questionnaire were provided on the KCS website.

\section{QoL Assessment}

There are several Korean versions of the questionnaires available for QoL assessment in patients with OAB. I-QOL and the ICIQ are mainly focused on QoL assessment. The KHQ and OAB-q questionnaire has QoL domains that were validated for $\mathrm{OAB}$ in both sexes. The BFLUTS questionnaire also has a QoL domain and was validated only for female patients with $\mathrm{OAB}$.

I-QOL is a self-reporting questionnaire for patients with incontinence, which was developed in 1996 [48]. The I-QOL items consisted of 3 subscales (avoidance and limiting behavior, psychosocial impacts, and social embarrassment) and 22 questions. I-QOL was translated and validated in 15 countries [49] and the Korean version of the I-QOL was linguistically validated in 2002 [23]. Psychometric property of the Korean version of the I-QOL was validated in 2009 [50]. I-QOL can be used to assess OAB symptoms in both sexes [51].

ICIQ is another self-completion questionnaire used to assess urinary incontinence and its impact on QoL [52]. ICIQ provides several different modules to measure specific symptoms of LUTS: ICIQ-OAB for OAB, ICIQ-N for nocturia, and ICIQMULUTS for male LUTS. The Korean version of the ICIQ was validated in 2006.

\section{Other PROMs}

The Patent Perception of Bladder Condition Measure [53] was developed to measure urinary incontinence. The European Medicine Evaluation Association recommends using the Patient Perception of Bladder questionnaire to evaluate $\mathrm{OAB}$ symptoms. The PPBC questionnaire shows reliable results in using $\mathrm{OAB}$ symptom assessment in 2 clinical trials [53]. The linguistic and psychometric validation of the Korean version of the PPBC was performed, and the available form is available on the KCS website.

The BSW questionnaire is focused on measuring PROs after $\mathrm{OAB}$ treatment. The BSW questionnaire was developed by Pfizer Corporation and consisted of 3 domains of PROs: treatment benefit, satisfaction with treatment, and willingness to continue treatment [54]. The BSW questionnaire successfully demonstrated the global impression of the net benefits of treatment outcomes for both clinical research and daily practice. The statements of the BSW reflect patients' attitudes and satis- faction with treatment. This questionnaire also shows the patient's compliance with medication [31]. The Korean version of the BSW is available with linguistic validation [31].

The Treatment Satisfaction Visual Analog Scale (TS-VAS) [32] and OAB-SAT-q [54] measure patients' satisfaction with their treatment on OAB. The TS-VAS uses a 100-mm-long horizontal line, and a patient makes a vertical mark on the line to convey their satisfaction of the treatment [55]. OAB-SAT-q contained 11 questions across 6 domains: effectiveness, convenience, side effects, preference of treatment, willingness to undergo treatment again, and global satisfaction. Both the TV-VAS and OABSAT-q were available for linguistic validation [32].

\section{Incontinence}

Urinary incontinence is an involuntary loss of urine that is classified by stress urinary incontinence (SUI), UUI, mixed urinary incontinence, nocturnal enuresis, and postural, continuous, insensible, and coital incontinence. Urgency can be combined with UUI; thus, most OAB questionnaires (KHQ, I-QOL, BFLUTS, ICIQ, and OABSS) contained incontinence domains. Both SUI and OAB are common in older females; thus, they can coexist. Several LUTS questionnaires have been validated for application in SUI. The KHQ obtained psychometric validation for application [56] and the ICIQ-UI short form is the most widely used questionnaire for patients with SUI [57].

\section{Adult Neurogenic Lower Urinary Tract Dysfunction}

Adult neurogenic lower urinary tract dysfunction (ANLUTD) is an abnormal or difficult lower urinary tract function in the context of clinically confirmed neurogenic disorders [58]. Patients who need clean intermittent catheterization (CIC) for bladder emptying in ANLUTD is up to 56\% in spinal cord injury and 75\% with multiple sclerosis [59]. To assess PROMs of patients who perform CIC, the intermittent self-catheterization questionnaire is available in the Korean version with linguistic validation [60]. The English version of the Qualiveen questionnaire, originally developed to measure the specific impact of urinary problems on the QoL of patients with neurogenic bladder, was linguistically validated in Korean in 2010 [61].

Although patients' QoL was severely altered in ANLUTD, there were no standard PROMs. Recently, the neurogenic bladder symptom score was developed and validated in the English version [62]. This questionnaire targeted the measurement of discomfort and QoL of ANLUTD, which can be a potential candidate for standard clinical use in patients with ANLUTD. 


\section{ISSUES IN QUESTIONNAIRE INTERPRETATION AND ANALYSIS}

There were several issues regarding the interpretation of the questionnaire results. First, most questionnaires used a Likert scale, which is one of the most widely used psychometric scales to measure the responders' attitude by several degrees of agreement with a statement. The Likert scale has an innate risk of bias that the researcher should be cautious of before analysis. If the variables show biased high estimates, patients tend to answer only low scores only (floor effect). In contrast, if the variables show biased low estimates, patients tend to answer high scores only (ceiling effect). Despite the changes in the independent variables, the changes in the dependent variable are not measurable, considering the ceiling or floor effect. In this situation, it is difficult to analyze the distribution of each degree because the score distribution is too low or too high. Therefore, the investigators must consider consistency and reliability before and after the tests for control and experimental groups and modify the statement for analysis.

Second, previous studies have shown that symptom scores and QoL do not directly reflect the severity of disease status. For example, BPH symptom scores do not accurately reflect the severity of LUTS, and several studies comparing questionnaire scores and urodynamic findings showed low correlations with urination muscle activity and bladder outlet obstruction [63-65].

\section{Future Perspectives}

There are still numerous questionnaires to be translated and validated. For example, detrusor underactivity is a complex of symptoms and bladder emptying problems related to urodynamic study-based abnormalities [66]. The prevalence of detrusor underactivity is reported in up to $40 \%$ of males and increases with age $[68,68]$. Although the importance of detrusor underactivity has been recently highlighted, no validated PROMs have been widely used $[69,70]$. Developing or translating the PROMs for sexual dysfunction in females is another issue. Severe LUTS can be correlated with sexual dysfunction in both males [71] and females [72]; however, there is still no standard questionnaire that directly measures female LUTS-related sexual function. The questionnaire focused on LUTS-related vaginal symptoms, and ANLUTD also needs to be validated.

\section{CONCLUSION}

In this review, we have summarized the established validation processes of the foreign language questionnaire before clinical use and explained the currently available questionnaires in Korean for LUTS. It is important to clearly determine the characteristics and limitations of each LUTS questionnaire to select the appropriate questionnaire for the clinical trial.

\section{AUTHOR CONTRIBUTION STATEMENT}

- Conceptualization: SYC

- Data curation: JS

- Formal analysis: SJO

- Project administration: SYC

- Writing-original draft: JS

-Writing-review \& editing: SJO

\section{REFERENCES}

1. Abrams P, Cardozo L, Fall M, Griffiths D, Rosier P, Ulmsten U, et al. The standardisation of terminology of lower urinary tract function: report from the standardisation sub-committee of the international continence society. Am J Obstet Gynecol 2002;187:11626.

2. Irwin DE, Milsom I, Hunskaar S, Reilly K, Kopp Z, Herschorn S, et al. Population-based survey of urinary incontinence, overactive bladder, and other lower urinary tract symptoms in five countries: results of the EPIC study. Eur Urol 2006;50:1306-15.

3. Coyne KS, Sexton CC, Thompson CL, Milsom I, Irwin D, Kopp ZS, et al. The prevalence of lower urinary tract symptoms (LUTS) in the USA, the UK and Sweden: results from the epidemiology of LUTS (EpiLUTS) study. BJU Int 2009;104:352-60.

4. Robertson C, Link CL, Onel E, Mazzetta C, Keech M, Hobbs R, et al. The impact of lower urinary tract symptoms and comorbidities on quality of life: the BACH and UREPIK studies. BJU Int 2007; 99:347-54.

5. Lokeshwar SD, Harper BT, Webb E, Jordan A, Dykes TA, Jr DEN, et al. Epidemiology and treatment modalities for the management of benign prostatic hyperplasia. Transl Androl Urol 2019;8:529-39.

6. Chughtai B, Forde JC, Thomas DDM, Laor L, Hossack T, Woo HH, et al. Benign prostatic hyperplasia. Nat Rev Dis Prim 2016;2:1-15.

7. Berry SJ, Coffey DS, Walsh PC, Ewing LL. The development of human benign prostatic hyperplasia with age. J Urol 1984;132:474-9.

8. Gulur DM, Drake MJ. Management of overactive bladder. Nat Rev 
Urol 2010;7:572-82.

9. Haylen BT, De Ridder D, Freeman RM, Swift SE, Berghmans B, Lee J, et al. An International Urogynecological Association (IUGA)/International Continence Society (ICS) joint report on the terminology for female pelvic floor dysfunction. Int Urogynecol J 2010;21:526.

10. Irwin DE, Kopp ZS, Agatep B, Milsom I, Abrams P. Worldwide prevalence estimates of lower urinary tract symptoms, overactive bladder, urinary incontinence and bladder outlet obstruction. BJU Int 2011;108:1132-9.

11. Gratzke C, Bachmann A, Descazeaud A, Drake MJ, Madersbacher $\mathrm{S}$, Mamoulakis $\mathrm{C}$, et al. EAU guidelines on the assessment of nonneurogenic male lower urinary tract symptoms including benign prostatic obstruction. Eur Urol 2015;67:1099-109.

12. Chua ME, Mendoza J, See M, Esmena E, Aguila D, Silangcruz JM, et al. A critical review of recent clinical practice guidelines on the diagnosis and treatment of non-neurogenic male lower urinary tract symptoms. Can Urol Assoc J 2015;9:E463-70.

13. Deborah J. Lightner, Alexander Gomelsky LS and SPVF. Diagnosis and treatment of overactive bladder (non-neurogenic) in adults: AUA/SUFU guideline amendment 2019. J Urol 2019;202:558-63.

14. Black N. Patient reported outcome measures could help transform healthcare. BMJ 2013;346:1-5.

15. Edwards P. Questionnaires in clinical trials: guidelines for optimal design and administration. Trials 2010;11:1-8.

16. Mokkink LB, Terwee CB, Patrick DL, Alonso J, Stratford PW, Knol $\mathrm{DL}$, et al. The COSMIN checklist for assessing the methodological quality of studies on measurement properties of health status measurement instruments: an international Delphi study. Qual Life Res 2010;19:539-49.

17. Lee JA, More SJ, Cotiw-an BS. Problems translating a questionnaire in a cross-cultural setting. Prev Vet Med 1999;41:187-94.

18. Wild D, Grove A, Eremenco S, McElroy S, Verjee-Lorenz A, Erikson $\mathrm{P}$. Principles of good practice for the translation and cultural adaptation process for patient-reported outcomes (PRO) measures: report of the ISPOR task force for translation and cultural adaptation. Value Heal 2005;8:94-104.

19. Cook DA, Beckman TJ. Current concepts in validity and reliability for psychometric instruments: theory and application 2006. Am J Med 2006;119:166.e7-16.

20. Donovan J, Abrams P, Peters T, Kay H, Reynard J, Chapple C, et al. The ICS-'BPH' Study: the psychometric validity and realibility of ICS male questionnaire. Br J Urol 1996;77:554-62.

21. Jackson S, Donovan J, Brookes S, Eckford S, Swithinbank L, Abrams P. The bristol female lower urinary tract symptoms ques- tionnaire: development and psychometric testing. Br J Urol 1996; 77:805-12.

22. Bright E, Cotterill N, Drake M, Abrams P. Developing and validating the international consultation on incontinence questionnaire bladder diary. Eur Urol 2014;66:294-300.

23. Oh SJ, Park HG, Lim SH, Hong SK, Martin ML, Ting BL, et al. Translation and linguistic validation of Korean version of the incontinence quality of life (I-QoL) instrument. J Korean Cont Soc 2002;6:10-23.

24. Oh SJ, Park HG, Paick SH, Park WH, Choo MS. Translation and linguistic validation of Korean version of the bristol female lower urinary tract symptom instrument. J Korean Cont Soc 2004;8:89113.

25. Oh SJ, Park HG, Paick SH, Park WH, Choo MS. Translation and linguistic validation of Korean version of the King's Health Questionnaire instrument. Korean J Urol 2005;46:438-50.

26. Oh SJ, Son H, Kim SW, Lee KS, Choo MS, Kim SO, et al. Psychometric properties of the korean version of the overactive bladder questionnaire (OAB-q) in a Korean population. Int Neurourol J 2012;16:77-85.

27. Kim SH, Oh SJ. Comparison of voiding questionnaires between female interstitial cystitis and female idiopathic overactive bladder. Int Neurourol J 2010;14:86-92.

28. Kim SE, Lee HS, Lee HN, Lee SY, Choo MS, Park MG, et al. Korean translation and linguistic validation of urgency and overactive bladder questionnaires. Int Neurourol J 2020;24:66-76.

29. Jeong SJ, Homma Y, Oh SJ. Korean version of the overactive bladder symptom score questionnaire: translation and linguistic validation. Int Neurourol J 2011;15:135-42.

30. Son HC, Jung YJ, Chang JS, Kim SH, Hong SK, Oh SJ, et al. Translation and linguistic validation of the korean version of the pelvic pain and urgency/frequency patient symptom scale. Int Neurourol J 2010;14:112-21.

31. Cho SY, Lee HE, Jeong SJ, Oh SJ. Translation and linguistic validation of the Korean version of the "benefit, satisfaction, and willingness to continue" questionnaire for patients with overactive bladder. Int Neurourol J 2016;20:255-9.

32. Lee HN, Chae JY, Lee HS, Choo MS, Park MG, Lee SY, et al. Translation and linguistic validation of the Korean version of the treatment satisfaction visual analogue scale and the overactive bladder satisfaction with treatment questionnaire. Int Neurourol J 2017;21: 309-19.

33. Kim DS, Chung BH. Translation validity and reliability of the Korean version of the DAN-PSS. Korean J Urol 2003;44:871-5.

34. Coyne K, Revicki D, Hunt T, Corey R, Stewart W, Bentkover J, et al. 
Psychometric validation of an overactive bladder symptom and health-related quality of life questionnaire: the OAB-q. Qual Life Res 2002;11:563-74.

35. Coyne KS, Thompson CL, Lai JS, Sexton CC. An overactive bladder symptom and health-related quality of life short-form: validation of the OAB-q SF. Neurourol Urodyn 2015;34:255-63.

36. Acquadro C, Kopp Z, Coyne KS, Corcos J, Tubaro A, Choo MS. Translating overactive bladder questionnaires in 14 languages. Urology 2006;67:536-40.

37. Homma Y, Yoshida M, Seki N, Yokoyama O, Kakizaki H, Gotoh M, et al. Symptom assessment tool for overactive bladder syndromeoveractive bladder symptom score. Urology 2006;68:318-23.

38. Homma Y, Gotoh M. Symptom severity and patient perceptions in overactive bladder: how are they related? BJU Int 2009;104:968-72.

39. Jeong SJ, Homma Y, Oh SJ. Reproducibility study of overactive bladder symptom score questionnaire and its response to treatment (RESORT) in Korean population with overactive bladder symptoms. Qual Life Res 2014;23:285-92.

40. Brookes ST, Donovan JL, Wright M, Jackson S, Abrams P. A scored form of the Bristol Female Lower Urinary Tract Symptoms questionnaire: data from a randomized controlled trial of surgery for women with stress incontinence. Am J Obstet Gynecol 2004;191: 73-82.

41. Kelleher CJ, Cardozo LD, Khullar V, Salvatore S. A new questionnaire to assess the quality of life of urinary incontinent women. $\mathrm{Br} J$ Obstet Gynaecol 1997;104:1374-9.

42. Okamura K, Nojiri Y, Osuga Y. Reliability and validity of the King's Health Questionnaire for lower urinary tract symptoms in both genders. BJU Int 2009;103:1673-8.

43. Minassian VA, Sun H, Yan XS, Clarke DN, Stewart WF. The interaction of stress and urgency urinary incontinence and its effect on quality of life. Int Urogynecol J Pelvic Floor Dysfunct 2014;26:26976.

44. Nixon A, Colman S, Sabounjian L, Sandage B, Schwiderski UE, Staskin DR, et al. A validated patient reported measure of urinary urgency severity in overactive bladder for use in clinical trials. J Urol 2005;174:604-7.

45. Lee KS, Lee HW, Choo MS, Paick JS, Lee JG, Seo JT, et al. Urinary urgency outcomes after propiverine treatment for an overactive bladder: the "propiverine study on overactive bladder including urgency data." BJU Int 2010;105:1565-70.

46. Notte SM, Marshall TS, Lee M, Hakimi Z, Odeyemi I, Chen WH, et al. Content validity and test-retest reliability of patient perception of intensity of urgency scale (PPIUS) for overactive bladder. BMC Urol 2012;12:1.
47. Cardozo L, Coyne KS, Versi E. Validation of the urgency perception scale. BJU Int 2005;95:591-6.

48. Wagner TH, Patrick DL, Bavendam TG, Martin ML, Buesching DP. Quality of life of persons with urinary incontinence: development of a new measure. Urology 1996;47:67-71.

49. Bushnell DM, Martin ML, Summers KH, Svihra J, Lionis C, Patrick DL. Quality of life of women with urinary incontinence: cross-cultural performance of 15 language versions of the I-QOL. Qual Life Res 2005;14:1901-13.

50. Oh SJ, Son H, Kim SW. Psychometric properties of the korean version of the incontinence quality of life instrument in women with stress urinary incontiennce. J Korean Cont Soc 2009;13:51-60.

51. Vandoninck V, Van Balken MR, Agrò EF, Petta F, Caltagirone C, Heesakkers JPFA, et al. Posterior tibial nerve stimulation in the treatment of urge incontinence. Neurourol Urodyn 2003;22:17-23.

52. Avery K, Donovan J, Peters TJ, Shaw C, Gotoh M, Abrams P. ICIQ: a brief and robust measure for evaluating the symptoms and impact of urinary incontinence. Neurourol Urodyn 2004;23:322-30.

53. Coyne KS, Matza LS, Kopp Z, Abrams P. The validation of the patient perception of bladder condition ( $\mathrm{PPBC})$ : a single-item global measure for patients with overactive bladder. Eur Urol 2006;49: 1079-86.

54. Pleil AM, Coyne KS, Reese PR, Jumadilova Z, Rovner ES, Kelleher CJ. The validation of patient-rated global assessments of treatment benefit, satisfaction, and willingness to continue - The BSW. Value Heal 2005;8 Suppl 1:S25-34. https://doi.org/10.1111/j.1524-4733. 2005.00069.x.

55. Brokelman RBG, Haverkamp D, van Loon C, Hol A, van Kampen A, Veth $R$. The validation of the visual analogue scale for patient satisfaction after total hip arthroplasty. Eur Orthop Traumatol 2012;3:101-5.

56. Oh SJ, Choo MS, Kim HS, Kim JC, Lee JG, Yun JM, et al. Psychometric properties of the Korean version of the King's health questionnaire in women with stress urinary incontinence. J Korean Cont Soc 2005;9:115-23.

57. Lim R, Liong ML, Leong WS, Yuen KH. Which outcome measures should be used in stress urinary incontinence trials? BJU Int 2018; 121:805-10.

58. Gajewski JB, Schurch B, Hamid R, Averbeck M, Sakakibara R, Agrò EF, et al. An International Continence Society (ICS) report on the terminology for adult neurogenic lower urinary tract dysfunction (ANLUTD). Neurourol Urodyn 2018;37:1152-61.

59. Kennelly M, Thiruchelvam N, Averbeck MA, Konstatinidis C, Chartier-Kastler E, Trøjgaard P, et al. Adult neurogenic lower urinary tract dysfunction and intermittent catheterisation in a com- 
munity setting: risk factors model for urinary tract infections. Adv Urol 2019;2019:2757862.

60. Kang SH, Oh SJ, Jeong SJ, Cho SY. Linguistic validation of the intermittent self-catheterization questionnaire for patients with neurogenic bladder who perform intermittent catheterization for voiding dysfunction. Int Neurourol J 2019;23:75-85.

61. Lee Y, Kim E, Oh SJ, Lee BS, Kim DA. The linguistic validation and reliability of the Korean version 'Qualiveen Questionnaire. J Korean Acad Rehab Med 2010;34:524-43.

62. Welk B, Morrow S, Madarasz W, Baverstock R, Macnab J, Sequeira $\mathrm{K}$. The validity and reliability of the neurogenic bladder symptom score. J Urol 2014:2-7.

63. Barry MJ, Cockett ATK, Holtgrewe HL, McConnell JD, Sihelnik SA, Winfield HN. Relationship of symptoms of prostatism to commonly used physiological and anatomical measures of the severity of benign prostatic hyperplasia. J Urol 1993;150:351-8.

64. Yalla SV, Sullivan MP, Lecamwasam HS, DuBeau CE, Vickers MA, Cravalho EG, et al. Correlation of American Urological Association symptom index with obstructive and nonobstructive prostatism. J Urol 1995;153:674-80.

65. Barry MJ. Evaluation of symptoms and quality of life in men with benign prostatic hyperplasia. Urology 2001;58:25-32.

66. Koeveringe GA Van, Rademakers KLJ, Birder LA, Korstanje C. Detrusor underactivity: pathophysiological considerations, models and proposals for future research. ICI-RS 2013 Gommert 2014; 33:591-6.

67. Jeong SJ, Kim HJ, Lee YJ, Lee JK, Lee BK, Choo YM, et al. Prevalence and clinical features of detrusor underactivity among elderly with lower urinary tract symptoms: a comparison between men and women. Korean J Urol 2012;53:342-8.

68. Kim M, Jung JH, Park J, Son H, Jeong SJ, Oh SJ, et al. Impaired detrusor contractility is the pathognomonic urodynamic finding of multiple system atrophy compared to idiopathic Parkinson's disease. Park Relat Disord 2015;21:205-10.

69. Uren AD, Cotterill N, Harding C, Hillary C, Chapple C, Klaver M, et al. Qualitative exploration of the patient experience of underactive bladder. Eur Urol 2017;72:402-7.

70. Tarcan T, Rademakers K, Arlandis S, von Gontard A, van Koeveringe GA, Abrams P. Do the definitions of the underactive bladder and detrusor underactivity help in managing patients: International Consultation on Incontinence Research Society (ICI-RS) Think Tank 2017? Neurourol Urodyn 2018;37:S60-8.

71. Gacci M, Eardley I, Giuliano F, Hatzichristou D, Kaplan SA, Maggi $\mathrm{M}$, et al. Critical analysis of the relationship between sexual dysfunctions and lower urinary tract symptoms due to benign prostatic hyperplasia. Eur Urol 2011;60:809-25.

72. Mota RL. Female urinary incontinence and sexuality. Int Braz J Urol 2017;43:20-8. 